\title{
Transfer of Electronic Excitation Energy between Randomly Mixed Dye Molecules in the Channels of Zeolite $\mathbf{L}$
}

\author{
Katsiaryna Lutkouskaya and Gion Calzaferri* \\ Department of Chemistry and Biochemistry, University of Bern, Freiestrasse 3, CH-3012 Bern, Switzerland
}

Received: November 1, 2005; In Final Form: January 11, 2006

\begin{abstract}
Host-guest materials containing strongly fluorescent donor and acceptor molecules have been prepared. Finetuning of the donor to acceptor distance in this material allows beautiful visible and quantitative observation of electronic excitation energy transfer phenomena. Oxonine and pyronine have been used as guest molecules and zeolite L as host. The dyes have been inserted by ion exchange. Stationary state and time-resolved experiments have been carried out with zeolite crystals of 300 and $700 \mathrm{~nm}$ size in the dye concentration range of $10^{-4} \mathrm{~mol} / \mathrm{L}$ up to $0.042 \mathrm{~mol} / \mathrm{L}$. The fluorescence decay of the donor and the pumping of the acceptor via energy transfer, which can be well observed, became faster with increasing loading. The behavior of the system follows requirements expected for Förster energy transfer material.
\end{abstract}

\section{Introduction}

Transfer and transport of electronic excitation energy have been of considerable interest within a wide range of systems and materials. ${ }^{1}$ We reported in a letter that interesting fluorescence resonance energy transfer (FRET) host-guest materials can be realized by keeping the ratio of the number of donor and acceptor molecules constant but decreasing their mean distance. ${ }^{2}$ It is usually not possible to achieve this over a large concentration range because of concentration quenching, e.g., due to the formation of aggregates. Our experiments were based on the idea that, if two strongly luminescent molecules of very similar structure but of sufficiently different absorption and fluorescence spectra can be inserted in an appropriate host at about the same speed, there is a chance to get random mixture of donors and acceptors inside the host. Zeolite $\mathrm{L}^{3}$ turned out to be a good host to realize such experiments. The two structurally very similar molecules, pyronine (Py) and oxonine $(\mathrm{Ox})$, can be inserted in its channels at about the same rate which results in zeolite $\mathrm{L}$ nanocrystals containing a random mixture of these strongly fluorescent donors (Py) and acceptors (Ox). The scheme of the resulting material, and the fluorescence and the absorption spectra of the Py and Ox molecules, are explained in Figure 1. The observations we published in ref 2 initiated research that led to highly interesting materials and observations, some of which have been reviewed in refs 4 and 5 . We have now investigated the electronic excitation energy transfer taking place from Py to Ox over a large concentration range, up to $0.042 \mathrm{M}$, to better characterize and understand this material, and we show that fine-tuning of the donor to acceptor distance allows beautiful visible and quantitative observation of electronic excitation energy phenomena.

\section{Experimental Section}

Materials. The pure potassium form of zeolite $\mathrm{L}\left(K_{9}\left(\mathrm{AlO}_{2}\right)_{9^{-}}\right.$ $\left.\left(\mathrm{SiO}_{2}\right)_{27} \cdot 21 \mathrm{H}_{2} \mathrm{O}\right)$ and the dyes, Py and $\mathrm{Ox}$, were synthesized and purified as described previously. ${ }^{6,7}$ The fluorescence decay

* Corresponding author e-mail: gion.calzaferri@iac.unibe.ch. of Ox and Py in zeolite L was reported to be typically $3.0 \mathrm{~ns}$ and $2.8 \mathrm{~ns}$, respectively. ${ }^{8}$ Typical zeolite L crystals used in this study had a length of 700 and $300 \mathrm{~nm}$ and a diameter of 640 and of $750 \mathrm{~nm}$, respectively.

Loading of Zeolite $\mathbf{L}$ with Py and Ox. (Py, Ox)-loaded zeolite L crystals were prepared by ion exchange. Six aqueous solutions of $3.9 \mathrm{~mL}$ containing the amount of 1 and $A$ : $4.86 \times$ $10^{-10} \mathrm{~mol} ; 2$ and $B: 1.21 \times 10^{-9} \mathrm{~mol} ; 3$ and $C: 2.43 \times 10^{-9}$ mol; 4 and $D: 4.86 \times 10^{-9} \mathrm{~mol} ; 5$ and $E: 9.72 \times 10^{-9} \mathrm{~mol}$; and 6: $1.94 \times 10^{-8} \mathrm{~mol}$ of each dye were prepared. The mixtures were stirred vigorously while $2 \mathrm{mg}$ of zeolite L (suspended in $100 \mu \mathrm{L}$ doubly distilled water) was added. The incorporation of the dyes was carried out by refluxing the samples at $100{ }^{\circ} \mathrm{C}$ for $18 \mathrm{~h}$. Aggregates were then removed from the surface of the crystals by washing the samples with a solution containing $10 \mu \mathrm{L}$ Genapol (Genapol X-080, Fluka) in $5 \mathrm{~mL}$ doubly distilled water. The amount of dye molecules inside the channels was determined by first destroying the zeolite framework with HF: $100 \mu \mathrm{L}$ of a $8 \%$ solution of $\mathrm{HF}$ was added to a solution of $3.9 \mathrm{~mL} n$-butanol containing $1 \mathrm{mg}$ of dye-loaded zeolite $\mathrm{L}$ in a polypropylene tube, and sonicated for $5 \mathrm{~min}$. The amount of dye left in the solution was determined by measuring the UV/Vis absorption spectrum.

Thin Layer Preparation. A quartz plate with a diameter of $8 \mathrm{~mm}$ was cleaned with doubly distilled water and ethanol. 2 $\mathrm{mg}$ of (Py, Ox)-loaded zeolite L material were suspended in 1 $\mathrm{mL}$ of 1-Butanol (Aldrich, for UV spectroscopy, >99.5\%) and $20 \mu \mathrm{L}$ of suspension was placed on a plate. Solvent was evaporated overnight at room temperature.

Steady-State Absorption and Fluorescence Measurements. UV/Vis spectra were recorded on a Perkin-Elmer Lambda 900 UV-Vis-NIR spectrometer, while a Perkin-Elmer LS 50 B was used to measure the fluorescence spectra.

Time-Resolved Fluorescence Measurements. The timeresolved fluorescence data were measured and analyzed as described in ref 8 . Measurements were carried out at room temperature. All the samples were excited at $465 \mathrm{~nm}$, corresponding to the maximum of Py absorption, and a $495 \mathrm{~nm}$ cutoff filter was used. The fluorescence was detected at 520 and 620 

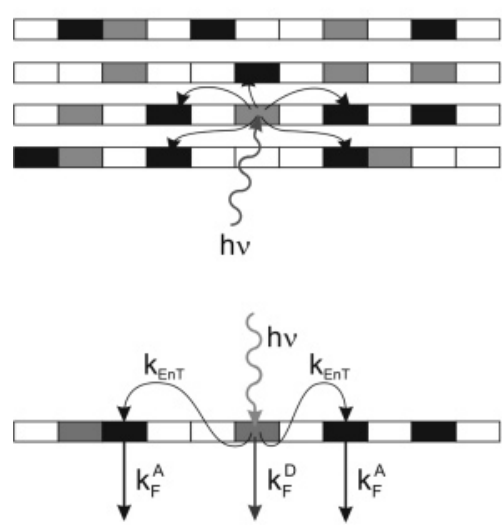

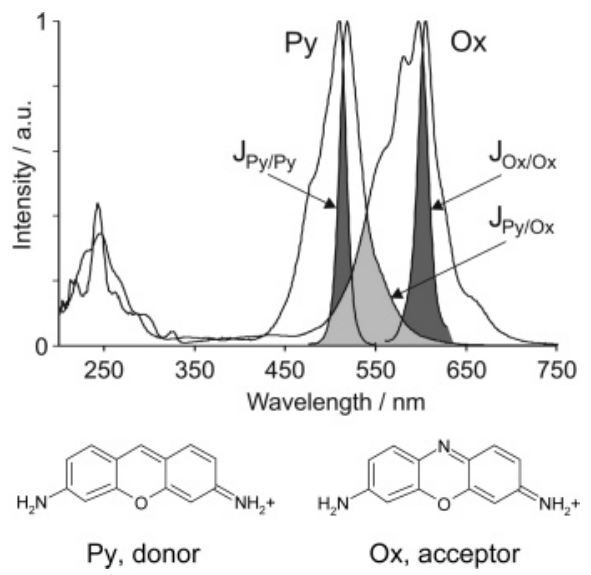

Figure 1. Overview of the system. Left: Scheme of a zeolite L crystal containing randomly mixed donor (D) and acceptor (A) molecules. Each rectangle marks a site which can be occupied by a dye molecule. The length of a rectangle is $15 \AA$ and the center to center distance between two channels is $18.4 \AA$. We show four channels containing donor (light gray rectangles) and acceptor (dark gray rectangles) molecules. The white rectangles are empty. The main processes taking place after excitation of a donor are energy transfer with the rate constant $k_{\mathrm{EnT}}$ and fluorescence of the donor and the acceptor with the rate constants $k_{\mathrm{F}}^{\mathrm{D}}$ and $k_{\mathrm{F}}^{\mathrm{A}}$, respectively. Right: Dyes used as a donor (Py) and as an acceptor $(\mathrm{Ox})$ and their excitation and fluorescence spectra in zeolite $\mathrm{L}$ scaled to the same height at the maximum. Three spectral overlap regions are indicated: those of the absorption and fluorescence of the individual dyes $\left(J_{\mathrm{Py} / \mathrm{Py}}\right.$ and $\left.J_{\mathrm{Ox} / \mathrm{Ox}}\right)$ and that of the fluorescence spectrum of Py with the absorption spectrum of Ox $\left(J_{\mathrm{Py} / \mathrm{Ox}}\right)$.

nm for Py and Ox fluorescence, respectively, with a resolution of $4 \mathrm{~nm}$ for all samples except for the lowest loading, where a resolution of $8 \mathrm{~nm}$ was used. Data analysis was performed with the Time-Resolved Frequency Domain Fitting Software v. 2.0 produced by Scientific Software Technologies Center, Minsk, Belarus.

\section{Results and Discussion}

While working with dye-loaded zeolite materials we like to use term "loading" instead of concentration. The relation between the loading $p$ and the concentration of Py or Ox in the zeolite $\mathrm{L}$ crystals in $\mathrm{mol} / \mathrm{L}$ is $c[\mathrm{~mol} / \mathrm{L}]=0.375 \cdot p .^{2,9}$ Loading means occupation probability of the zeolite channels: ratio of sites occupied with dyes to the total amount of sites available. We use the symbol $p_{1 / 2}$ when describing samples which contain the same amount of Py and of Ox to express the fact that the total dye concentration in such samples is $2 \cdot p_{1 / 2}$.

Figure 2 shows results obtained for seven fluorescent samples bearing similar information as reported in refs 2,5 , and $9 \mathrm{~b}$. Zeolite L crystals of $300 \mathrm{~nm}$ average length were filled as follows: The two references Py and Ox were loaded with $5 \times$ $10^{-3} \mathrm{M}$ of Py and $5 \times 10^{-3} \mathrm{M}$ of $\mathrm{Ox}$, respectively. The other samples contain a 1:1 mixture of Py and Ox of the following concentrations: $A, 2 \times\left(5 \times 10^{-4} \mathrm{M}\right.$ or $\left.\mathrm{p}_{1 / 2}=0.0014\right) ; B, 2 \times$ $\left(1.25 \times 10^{-3} \mathrm{M}\right.$ or $\left.\mathrm{p}_{1 / 2}=0.0035\right) ; C, 2 \times\left(2.5 \times 10^{-3} \mathrm{M}\right.$ or $\left.\mathrm{p}_{1 / 2}=0.007\right) ; D, 2 \times\left(5.0 \times 10^{-3} \mathrm{M}\right.$ or $\left.\mathrm{p}_{1 / 2}=0.014\right)$; and $E$, $2 \times\left(1.0 \times 10^{-2} \mathrm{M}\right.$ or $\left.\mathrm{p}_{1 / 2}=0.028\right)$. The mean distance $R_{\mathrm{Py}, \mathrm{Ox}}$ in $\AA$ between the Py and Ox molecules in the $A$ to $E$ hostguest materials can be estimated to be $R_{\mathrm{Py}, \mathrm{Ox}} \approx 7.35 \cdot c_{\mathrm{Ox}}{ }^{-1 / 3}$, where $c_{O x}$ is the $\mathrm{Ox}$ concentration expressed in $\mathrm{mol} / \mathrm{L} .^{5 \mathrm{a}}$ Excitation was, in all cases at $485 \mathrm{~nm}$, where the absorption of Py is strong and that of Ox very weak, as can be seen from the absorption spectra given in Figure 1. We observe in sample $\boldsymbol{A}$ mainly the green fluorescence of Py, which indicates that energy transfer is insignificant. But the yellow color of sample $\boldsymbol{B}$ is due to a mixture of green and red fluorescence which means that energy transfer is significant in this sample. It becomes more and more important with increasing concentration so that from sample $\boldsymbol{E}$ on, the red fluorescence stemming from Ox is dominant, hence, the intensity of the Ox emission increases with

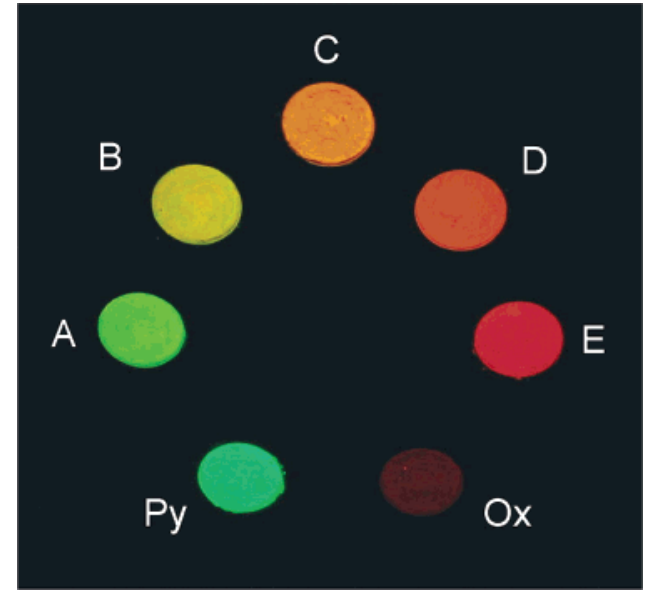

Figure 2. Visual demonstration of energy transfer: Photographic picture of the fluorescence of dye-loaded zeolite L layers upon monochromatic irradiation at $485 \mathrm{~nm}$ through an interference filter and observation through a $500 \mathrm{~nm}$ cutoff filter. Py and Ox are references loaded with Py and Ox. Samples A to E contain a 1:1 mixture of Py and $\mathrm{Ox}$ with the following loading for each dye: $\mathrm{A}, \mathrm{p}_{1 / 2}=0.0014 ; \mathrm{B}$, $\mathrm{p}_{1 / 2}=0.0035 ; \mathrm{C}, \mathrm{p}_{1 / 2}=0.007 ; \mathrm{D}, \mathrm{p}_{1 / 2}=0.014 ;$ and $\mathrm{E}, \mathrm{p}_{1 / 2}=0.028$.

increasing concentration. This visual demonstration of energy transfer can be quantified by measuring the fluorescence spectra of such materials coated on a quartz support. ${ }^{10}$

It is possible to do measurements over a larger concentration range than what was reported earlier and in Figure 2. However, considerable self-absorption occurs due to the very high absorptivity of the individual crystals. Results of measurements scanning a larger concentration range, namely from $2 \cdot\left(10^{-4} \mathrm{~mol} /\right.$ L) up to $2 \cdot(0.021 \mathrm{~mol} / \mathrm{L})$, which corresponds to $p_{1 / 2}=0.0014$ up to $p_{1 / 2}=0.056$, are illustrated in Figure 3 . In this case zeolite $\mathrm{L}$ crystals of $700 \mathrm{~nm}$ average length were used. The excitation spectra in Figure 3(left) were recorded at $650 \mathrm{~nm}$. The samples 1 to 4 show that the amount of energy transfer from Py to Ox increases with increasing concentration. However, this seems not to be the case for $\mathbf{5}$ and $\mathbf{6}$. This apparent discrepancy and the broadening of the bands are due to self-absorption caused by the high concentration. The same phenomenon is seen in the fluorescence spectra, Figure 3(right). A significant batho- 

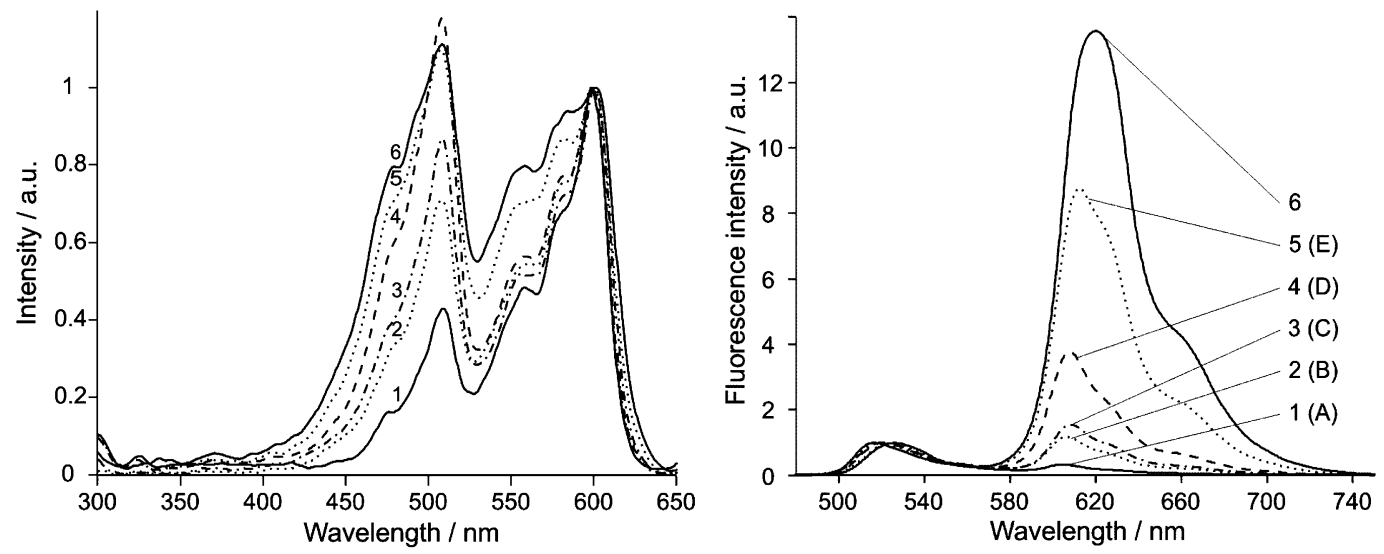

Figure 3. Excitation and emission spectra of series of six samples containing a 1:1 mixture of Py and Ox with the following loadings of each dye: $\mathbf{1}, \mathrm{p}_{1 / 2}=0.0014 ; \mathbf{2}, \mathrm{p}_{1 / 2}=0.0035 ; \mathbf{3}, \mathrm{p}_{1 / 2}=0.007 ; \mathbf{4}, \mathrm{p}_{1 / 2}=0.014 ; \mathbf{5}, \mathrm{p}_{1 / 2}=0.028$; and $\mathbf{6}, \mathrm{p}_{1 / 2}=0.056$. Left: Excitation spectra observed at 650 $\mathrm{nm}$, scaled to the same peak height for the Ox emission at about $600 \mathrm{~nm}$. Right: Fluorescence spectra after excitation of Py at $450 \mathrm{~nm}$, scaled to the same peak height for the Py emission at about $520 \mathrm{~nm}$. The letters in brackets (A to E) indicate that these spectra correspond roughly to samples A to E in Figure 2.

chromic shift and a distortion at longer wavelengths is obvious in 5 and 6 while samples 1 to 4 behave again as expected. Details concerning self-absorption in similar materials have been discussed in refs 8 and $9 \mathrm{~b}$

We consider the following processes:

$$
\begin{gathered}
D \rightarrow D^{*} \quad \text { excitation } \\
A+D^{*} \stackrel{k_{E n T}}{\longrightarrow} A^{*}+D \quad \text { energy transfer } \\
D^{*} \stackrel{k_{F}^{D}}{\longrightarrow} D+h v \quad \text { fluorescence of the donor } \\
A^{*} \stackrel{k_{F}^{A}}{\longrightarrow} A+h v \quad \text { fluorescence of the acceptor }
\end{gathered}
$$

Here $k_{F}^{D}$ and $k_{F}^{A}$ are the fluorescence rate constants of the donor and the acceptor, respectively. The time dependent concentrations of the donors and the acceptors in the excited singlet state $S_{1},\left[D^{*}\right]$ and $\left[A^{*}\right]$ can be expressed as follows: $10 \mathrm{~b}$

$$
\begin{aligned}
& \frac{d\left[D^{*}\right]}{d t}=-\left[D^{*}\right]\left(k_{E n T}+\sum_{d} k_{d}^{D}\right) \\
& \frac{d\left[A^{*}\right]}{d t}=\left[D^{*}\right] k_{E n T}-\left[A^{*}\right] \sum_{a} k_{a}^{A}
\end{aligned}
$$

$k_{E n T}$ is the rate constant of $D^{*}$ to $A$ energy transfer, $k_{d}^{D}$ and $k_{a}^{A}$ are the rate constants of other deactivation processes of $D^{*}$ and $A^{*}$, respectively. The rate constant for Förster energy transfer $k_{E n T}$ can be expressed as follows: ${ }^{10}$

$$
k_{E n T}=\frac{9000 \ln (10)}{128 \pi^{5} N_{L}} \frac{\kappa_{D^{* A}}^{2}}{n^{4} R^{6}} \frac{\phi_{0, D}}{\tau_{0, D}} J
$$

where $R$ is the distance between the donor and the acceptor in $\AA$, and $N_{L}$ is Avogadro's number in $\mathrm{mol}^{-1} \cdot \kappa_{D^{* A}}^{2}$ describes the dependence of the energy transfer rate constant on the relative orientation of the electronic transition dipole moments of $D^{*}$ and $A$. $\phi_{0, D}=k_{F} D / \sum_{d} k_{d}^{D}$ is the fluorescence quantum yield of the donor and $\tau_{0, D}$ is the fluorescence decay time of the donor in absence of energy transfer in ns (we distinguish between the intrinsic decay time of the donor $\tau_{i n, D}=1 / k_{F}^{D}$ and the decay time $\left.\tau_{0, D}=\phi_{0, D} \tau_{i n, D}=1 / \sum_{d} k_{d}^{D}\right) . J$ is the spectral overlap integral of donor fluorescence and acceptor absorption in $\mathrm{cm}^{3} \mathrm{M}^{-1}$ :

$$
J=\int_{\bar{v}} S_{D}(\bar{v}) \frac{\epsilon_{A}(\bar{v})}{\bar{v}^{4}} d \bar{v}
$$

The molar extinction coefficient $\epsilon_{A}(\bar{v})$ is expressed in $\mathrm{M}^{-1} \mathrm{~cm}^{-1}$. Taking units of all the parameters into account, the dimension of the energy transfer rate constant is $\mathrm{ns}^{-1}$.

At a specific $D^{*} \ldots . A$ distance, the rate at which $D^{*}$ emits light is equal to the rate at which it transfers its excitation energy to $A$. This donor to acceptor distance is called Förster radius, $R_{0}$. From eq 7 one finds:

$$
R_{0}=\sqrt[6]{\frac{9000 \ln (10)}{128 \pi^{5} N_{L}} \frac{\kappa_{D^{*} A}^{2}}{n^{4}} \phi_{0, D} J}
$$

Combining eqs 7 and 9 yields the simple but very useful formula 10. It allows determining the rate constant of energy transfer as a function of distance: ${ }^{10}$

$$
k_{E n T}=\frac{1}{\tau_{0, D}}\left(\frac{R_{0}}{R}\right)^{6}
$$

The spectral overlap, $J$, between the emission of an electronically excited $D^{*}$ and $A$ is defined in eq 8 . Knowing the spectral overlap integral, we can calculate the Förster radius $R_{0}$ according to eq 9. From the Förster radius and the fluorescence lifetime of the donor in the absence of energy transfer, we can calculate the energy transfer rate constant according to ref 10 . Values for the two molecules under investigation are given in Table 1 for two different values of $\kappa_{D^{* A}}^{2}$ and two distances $R$. From this we see, that rate constants in the order of $10^{12} \mathrm{~s}^{-1}$ have to be considered as being quite common and, in favorable cases, rate constants in the order of a few times $10^{13} \mathrm{~s}^{-1}$ should be possible. The orientation of the $\mathrm{Ox}$ and Py molecules in the channels of zeolite L crystals with respect to the channel axis can be determined from fluorescence polarization measurements of single crystals. It was found that a double cone distribution is a valuable model for interpreting the fluorescence polarization data. Quantitative measurements on Ox in zeolite L, which is very similar to $\mathrm{Py}$, revealed a half cone angle of $72^{\circ} .{ }^{11}$ Based 
TABLE 1: Spectral Overlap, Förster Radius for Two Values of $\kappa_{D^{* A}}^{2}$, and Energy Transfer Rate Constant for Molecules in Zeolite $\mathrm{L}$ at Room Temperature $\left(\mathrm{J}\right.$ and $\tau_{0, D}$ are Experimental Values)

\begin{tabular}{ccccccc}
\hline \multirow{2}{*}{$\begin{array}{c}\text { dyes: } \\
\text { donor/acceptor }\end{array}$} & $J / \mathrm{cm}^{3} \mathrm{M}^{-1}$ & $\kappa_{D^{*} \mathrm{~A}}^{2}$ & $R_{0} / \AA$ & $\tau_{0, D} / \mathrm{ns}$ & $R=R_{0}$ & $R=15 \AA$ \\
\hline Ox/Ox & $4.4 \times 10^{-13}$ & $2 / 3$ & 64 & 3.2 & 0.31 & 1900 \\
& & 4 & 86 & & & 11000 \\
Py/Py & $1.1 \times 10^{-13}$ & $2 / 3$ & 51 & 3 & 0.33 & 500 \\
& & 4 & 68 & & & 2900 \\
Py/Ox & $2.3 \times 10^{-13}$ & $2 / 3$ & 57 & 3 & 0.33 & 1000 \\
& & 4 & 77 & & & 6000
\end{tabular}

on this, the value of $\kappa_{D^{* A}}^{2}$ in the (Py, Ox)-zeolite $\mathrm{L}$ material has been estimated numerically to be about one by using the method as described in ref $9 \mathrm{a}$.

A quantity we can measure with good accuracy in this material is the ratio between the two fluorescence quantum yields $\phi_{D}$ and $\phi_{A}$ of $D$ and $A$ when energy transfer takes place. According to schemes $1-4$ and the corresponding equations 5 and $6, \phi_{D}$ and $\phi_{A}$ are

$$
\phi_{D}=\frac{k_{F}^{D}}{k_{E n T}+\sum_{d} k_{d}^{D}} \text { and } \phi_{\mathrm{A}}=\frac{k_{E n T}}{k_{E n T}+\sum_{d} k_{d}^{D}} \frac{k_{F}^{A}}{\sum_{a} k_{a}^{A}}
$$

Their ratio is equal to the ratio of the corresponding fluorescence intensities $I_{F}^{A}$ and $I_{F}^{D}$.

$$
\frac{I_{F}^{A}}{I_{F}^{D}}=k_{E n T} \frac{k_{F}^{A}}{k_{F}^{D} \sum_{a} k_{a}^{A}}=k_{E n T} \tau_{i n, D} \phi_{0, A}
$$

From this we expect, by averaging over many situations, a linear relationship between the ratio of the acceptor to donor intensities, with respect to the loading which we express as follows: ${ }^{9 \mathrm{~b}}$

$$
\frac{I_{F}^{A}}{I_{F}^{D}}=C p_{1 / 2}
$$

where $C$ is a constant. This leads to eq 14 which gives an estimate of a mean energy transfer rate constant.

$$
\left\langle k_{E n T}\right\rangle=\frac{1}{\phi_{0, A} \tau_{i n, D}} C p_{1 / 2}
$$

Plotting the ratio of intensities for the same series as in Figure 3 versus loading at three acceptor wavelengths, namely the maximum of the emission, $625 \mathrm{~nm}$ and $650 \mathrm{~nm}$, we obtain the result presented in Figure 4. We observe that the 625 and 650 $\mathrm{nm}$ data follow eq 13 well, while the last point when plotting the emission maximum data is much too low. The reason for this is that the fluorescence spectrum of Ox is not affected at 625 and $650 \mathrm{~nm}$ by the self-absorption process while it is affected at shorter wavelengths. This is consistent with the data in Figure 3. We further observe that the lines do not start at $p_{1 / 2}=0$, which is due to some absorptivity of the acceptor Ox at $450 \mathrm{~nm}$, as can be seen in Figure 1. This can, however, be easily taken into account, since the small contribution of the fluorescence coming from this direct excitation increases linearly with increasing Ox concentration. The fitting of eq 13 to the data points in Figure 4 was carried out accordingly. The resulting

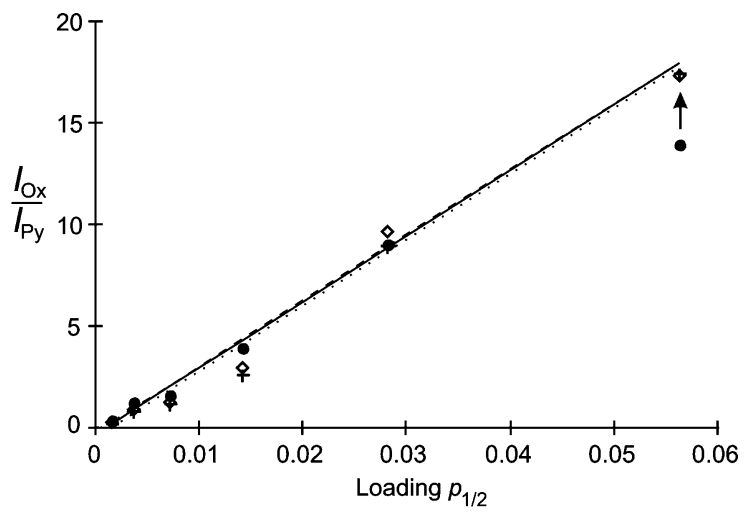

Figure 4. Ratio of the fluorescence intensities of the acceptor $\left(\mathrm{I}_{\mathrm{Ox}}\right)$ and the donor $\left(\mathrm{I}_{\mathrm{Py}}\right)$ as a function of the loading $\mathrm{p}_{1 / 2}$ for the same series as in Figure 3. The points represent the experimental data and the lines were fitted according to eq 13: solid line and $(\bullet)$ refer to the maximum of the emission, dotted line and $(\diamond)$ refer to $625 \mathrm{~nm}$, dashed lines and $(+)$ refer to $650 \mathrm{~nm}$. The arrow indicates that the maximum of the emission is distorted due to self-absorption and re-emission of the Ox.

slope $C$ is 320 . Knowing the slope $C$ over a considerable concentration range, we can estimate the mean energy transfer rate constant according to eq 14. Assuming a ratio of the donor to acceptor fluorescence quantum yields of 1 and an intrinsic decay time of the donor of $3 \mathrm{~ns}$, we can extrapolate for a full loading $p_{1 / 2}=0.5$ that $\left\langle k_{E n T}\right\rangle$ in this system is on the order of $5 \times 10^{10} \mathrm{~s}^{-1}$. This is in good agreement with an estimate we can make by using eq 10 , which leads to the same result if we assume a mean distance of $2.6 \mathrm{~nm}$, which is a reasonable value.

We now discuss the time dependence of the donor and of the acceptor fluorescence. Any acceptor molecule $A_{\mathrm{i}}$, at distance $R_{\mathrm{i}}$ from $D^{*}$, gives an additional channel for relaxation, the rate constant of which is $k_{E n T}(i)$ :

$$
k_{E n T}(i)=\frac{1}{\tau_{0, D}}\left(\frac{R_{0}}{R_{i}}\right)^{6}
$$

The time dependence of the donor intensity in a threedimensional system follows stretched-exponential eq 16:10,12

$$
I_{D}(t)=e^{-t / \tau_{0, D}} e^{-2 \gamma \sqrt{t / \tau_{0, D}}}
$$

where we have $\gamma=\sqrt{\pi} / 2 c_{A} 4 \pi / 3 R_{0}^{3} N_{\mathrm{L}} . c_{A}$ is the concentration of the acceptor molecules. The average number of acceptor molecules in a sphere of radius $R$ is given by $c_{A} 4 \pi / 3 R^{3} N_{L}$. The critical concentration of acceptor molecules is represented by $c_{0}=3 / 2 \pi^{3 / 2} 1 / N_{L} R_{0}{ }^{3}$. Hence, $\gamma$ can be expressed as ratio between the actual concentration of acceptor molecules and the critical concentration $c_{0}$ :

$$
\gamma=\frac{c_{A}}{c_{0}}
$$

We observe that, despite the fact that each excited donor molecule $D^{*}$ decays strictly according to a monoexponential law, the mean decay of an ensemble of donor molecules is not a single exponential, but becomes faster with an increasing value of $\gamma$. Due to the small size of the zeolite L host crystals and the anisotropy, some confinement in space is felt by the ensemble of molecules. This can be taken into account by extending eq 16 and introducing the parameter $\delta$ as expressed in eq $18 . \delta$ has been shown to be equal to $1 / 2$ in three-dimensional systems 

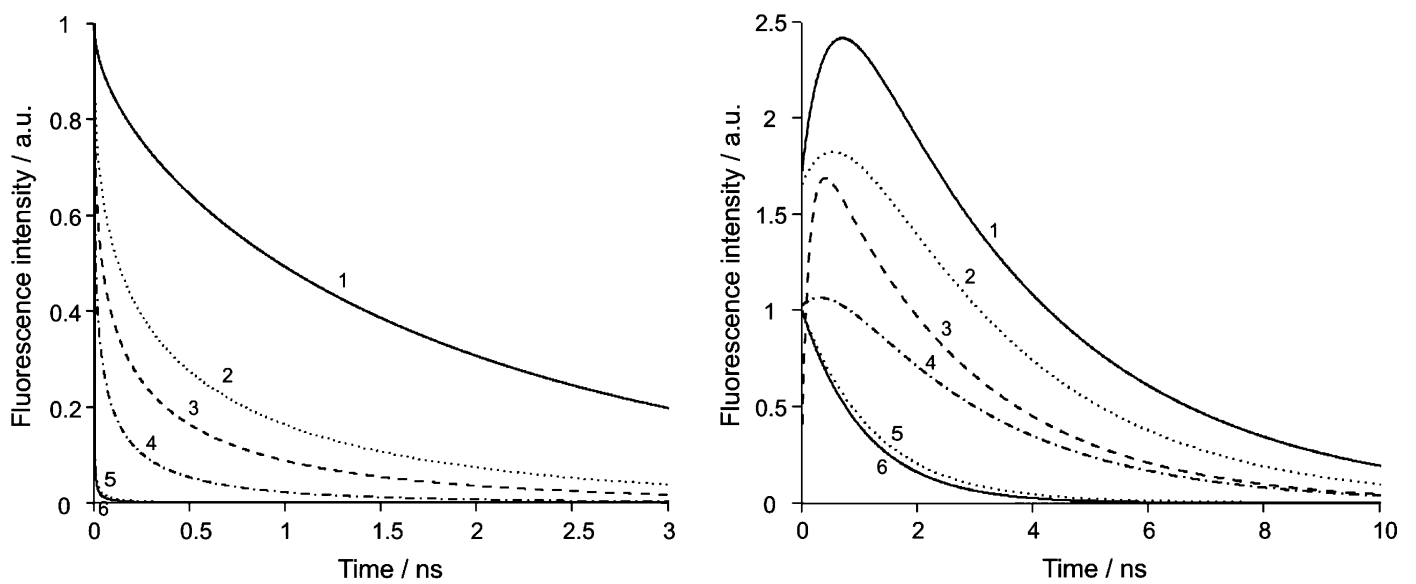

Figure 5. Fluorescence intensities of the donor and the acceptor versus time of the same series as reported in Figures 3 and 4 . Left: Intensity of the donor Py emission upon excitation at $465 \mathrm{~nm}$ and observation at $520 \mathrm{~nm}$. Right: Intensity of the acceptor Ox emission upon excitation of Py at $465 \mathrm{~nm}$ and observation at $620 \mathrm{~nm}$.

TABLE 2: Decay Parameters of the Fluorescence Intensity of the 1:1 (Py,Ox)-zeolite L Material at Different Loadings $p_{1 / 2}$ upon Excitation at $465 \mathrm{~nm}$

\begin{tabular}{ccccccccccc}
\hline & & \multicolumn{3}{c}{$\begin{array}{c}\text { donor observed } \\
\text { at } 520 \mathrm{~nm}\end{array}$} & & \multicolumn{4}{c}{$\begin{array}{c}\text { acceptor observed } \\
\text { at } 620 \mathrm{~nm}\end{array}$} \\
\cline { 7 - 9 } sample & $\begin{array}{c}\text { loading } \\
p_{1 / 2}\end{array}$ & $2 \gamma$ & $\delta$ & $\tau_{0, D} / n s$ & & $\mathrm{a}_{1}$ & $\tau_{1} / n s$ & $\mathrm{a}_{2}$ & $\tau_{2} / n s$ \\
\hline $\mathbf{1}$ & 0.0014 & 0.63 & 0.459 & 3.0 & & 0.67 & 3.49 & -0.33 & 0.46 \\
$\mathbf{2}$ & 0.0035 & 2.30 & 0.395 & 3.0 & & 0.70 & 2.94 & -0.30 & 0.72 \\
$\mathbf{3}$ & 0.007 & 3.12 & 0.353 & 3.0 & & 0.55 & 2.61 & -0.45 & 0.14 \\
$\mathbf{4}$ & 0.014 & 5.11 & 0.337 & 3.0 & & 0.76 & 2.74 & -0.24 & 0.56 \\
$\mathbf{5}$ & 0.028 & 9.95 & 0.218 & 3.0 & & 0.04 & 3.0 & 0.96 & 1.21 \\
$\mathbf{6}$ & 0.056 & 11.5 & 0.229 & 3.0 & & 0.24 & 1.29 & 0.76 & 0.08
\end{tabular}

and becomes smaller as the dimensionality decreases: $1 / 3$ and $1 / 6$ for two- and one-dimensional systems, respectively. ${ }^{12}$

$$
I_{D}(t)=e^{-t / \tau_{0, D}} e^{-2 \gamma\left(t / \tau_{0, D}\right)^{\delta}}
$$

The change in excited acceptor concentration obeys the differential equations 5 and 6 . The solution of these equations with the initial conditions $\left[D^{*}\right](t=0)=\left[\mathrm{D}^{*}\right]_{0}$ is: ${ }^{10 \mathrm{~b}}$

$$
\left[A^{*}\right]=\frac{\left[D^{*}\right]_{0} k_{E n T}}{1 / \tau_{D}-1 / \tau_{0, A}}\left(e^{-t / \tau_{0, A}}-e^{-t / \tau_{D}}\right)
$$

where $\tau_{D}=1 / \sum_{d} k_{d}^{D}+k_{E n T}$ is the fluorescence decay time of the donor in the presence of energy transfer and $\tau_{0, A}=1 / \sum_{a} k_{a}^{A}$ is the fluorescence decay time of the acceptor in absence of energy transfer. Equation 19 suggests that a dual exponential function with a term that describes the raising of the acceptor fluorescence intensity and a term that describes its decay is expected to be a valid approximation. Markow chain calculations as explained in ref $9 \mathrm{a}$ do support this. Hence, the intensity dynamics of the acceptor can be expressed as follows:

$$
I_{A}(t)=a_{1} e^{-t / \tau_{1}}+a_{2} e^{-t / \tau_{2}}
$$

We have observed that the experimental results can be well described by means of eqs 18 and 20 . The fluorescence intensity decays of the donor and the acceptor for the same samples as in Figures 3 and 4 are shown in Figure 5; fitted parameters are given in Table 2. The fluorescence decay of the donor becomes faster with increasing loading since the energy transfer process becomes more important than the fluorescence of the donor. The pre-exponential factor $a_{2}$ in the acceptor fluorescence decay of samples 1 to 4 has a negative value because the fluorescence intensity has to build up before it starts to decay. This means

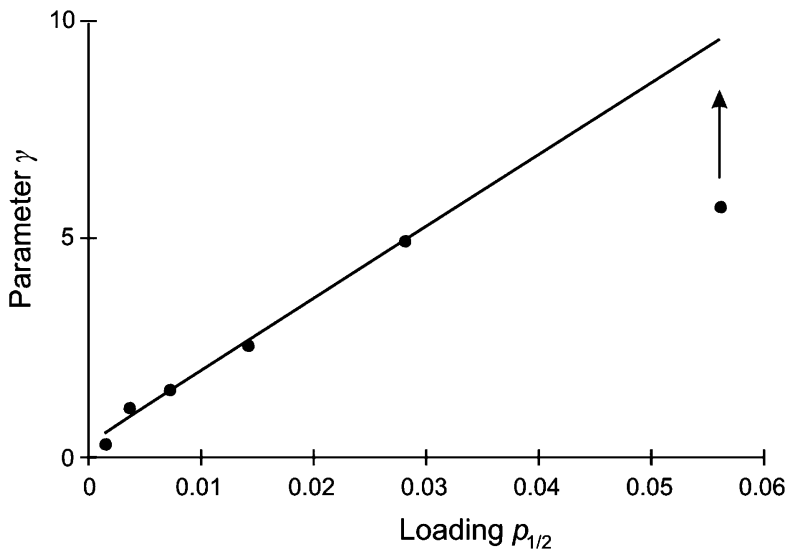

Figure 6. Plot of the values of $\gamma$ versus the loading. The circles are the measured data points and the line was fitted according to eq 17 , by omitting point number 6 .

that the acceptors are first "pumped" by means of energy transfer before they can start to decay. Experimental observation of this "pumping of the acceptors" in systems where the fluorescence lifetime is only a few ns is often difficult. We are fortunate in the present case. The build up of the intensity becomes faster and faster with increasing loading, which means decreasing donor-acceptor mean distance. This compares well with observations made recently for dye-zeolite L antenna materials. ${ }^{5,13}$

Plotting the values of $\gamma$ reported in Table 2 versus the loading (see Figure 6), one would expect to obtain a straight line, according to eq 17. This is indeed the case, with the exception of sample $\mathbf{6}$ for which it is difficult to interpret the fluorescence decay data because of the very pronounced self-absorption taking place. A further interesting observation is that the parameter $\delta$ describing the dimensionality of the system decreases with increasing loading, which can be interpreted as a decrease of the systems dimensionality. This is consistent with other observations we have recently made. ${ }^{13}$

\section{Conclusions}

Varying the mean distance between donor and acceptor molecules allows fine-tuning of the amount of energy transfer, the fluorescence dynamics, and the color of the material. The behavior of the system follows all requirements expected for Förster energy transfer material. The contribution of selfabsorption and re-emission becomes important above a certain 
concentration, as expected. It manifests itself so clearly that it can be well separated. The experiments described have been carried out with crystals of 300 and $700 \mathrm{~nm}$ length. Similar experiments can be done with zeolite L crystals of any size between $30 \mathrm{~nm}$ and up to $7000 \mathrm{~nm} .{ }^{6}$ Recently the preparation of crystals of more than $10 \mu \mathrm{m}$ length has been reported. ${ }^{14}$ The loading of such large crystals by cation exchange can be tedious. Loading of neutral dyes from the gas phase is often easier. ${ }^{5}$ An alternative procedure was used for preparing panchromatic chromophore mixtures in an AlPO-5 molecular sieve ${ }^{15}$ and a different type of organic-inorganic material prepared by a solgel procedure ${ }^{16}$ has been described recently. If a blue emitting dye is added to the 1:1 (Py,Ox)-zeolite $\mathrm{L}$ material, white light emission from the individual crystals can be observed, provided that the mixing of blue, green, plus red emission is well adjusted, hence, offering interesting options for nano-optics.

Acknowledgment. We would like to thank Dr. André Devaux for many helpful discussions and to René Bühler for making the samples and the photographic picture for the visual experiment in Figure 2. This work was supported by the Swiss National Science Foundation projects NFP-47 (4047-57481) and NF200020-105140/1.

Note Added after ASAP Publication. Equation 9 has been corrected. This paper was published on the Web on February 21, 2006; the corrected version was reposted on February 27, 2006.

\section{References and Notes}

(1) (a) Balaban, T. S. Acc. Chem. Res. 2005, 38, 612. (b) SanchoGarcía, J. C.; Brédas, J.-L.; Beljonne, D.; Cornil, J.; Martínez-Álvarez, R.; Hanack, M.; Poulsen, L.; Gierschner, J.; Mack, H.-G.; Egelhaaf, H.-J.; Oelkrug., D. J. Phys. Chem. B 2005, 109, 4872. (c) De Schryver, F. C.; Vosch, T.; Cotlet, M.; van der Auweraer, M.; Müllen, K.; Hofkens, J. Acc.
Chem. Res. 2005, 38, 514. (d) Tinnefeld, P.; Sauer, M. Angew. Chem., Int. Ed. 2005, 44, 2642. (e) Håkansson, P.; Isaksson, M.; Westlund, P.-O.; Johansson, L. B. A. J. Phys. Chem. B 2004, 108, 17243.

(2) Gfeller, N.; Megelski, S.; Calzaferri, G. J. Phys. Chem. B 1998, 102, 2433.

(3) (a) Breck, D. W. Zeolite Molecular Sieves: Structure, Chemistry, and Use; John Wiley and Sons: New York, 1974. (b) Baerlocher, Ch.; Meier, W. M.; Olson, D. H. Atlas of Zeolite Framework Types 5th ed.; Elsevier: Amsterdam, 2001.

(4) (a) Thomas, J. K. Chem. Rev. 2005, 105, 1683. (b) Hashimoto, S. J. Photochem. Photobiol. C 2003, 4, 19. (c) Schulz-Ekloff, G.; Wöhrle, D.; van Duffel, B.; Schoonheydt, R. A. Microporous Mesoporous Mater. 2002, 51, 91 .

(5) (a) Calzaferri, G.; Huber, S.; Maas, H.; Minkowski, C. Angew. Chem., Int. Ed. 2003, 42, 3732. (b) Minkowski, C.; Pansu, R.; Takano, M.; Calzaferri, G. Adv. Funct. Mater. 2006, 16, 273. (c) Calzaferri, G.; Bossart, O.; Brühwiler, D.; Huber, S.; Leiggener, C.; Van Veen, M. K. Zabala Ruiz, A. C. R., Chimie 2006, 9, 214.

(6) (a) Megelski, S.; Calzaferri, G. Adv. Funct. Mater. 2001, 11, 277. (b) Zabala Ruiz, A.; Brühwiler, D.; Ban, T.; Calzaferri, G. Monatsh. Chem. 2005, 136, 77.

(7) Maas, H.; Khatyr, A.; Calzaferri, G. Microporous Mesoporous Mater. 2003, 65, 233.

(8) Yatskou, M. M.; Meyer, M.; Huber, S.; Pfenniger, M.; Calzaferri, G. ChemPhysChem 2003, 4, 567.

(9) (a) Gfeller, N.; Calzaferri, G. J. Phys. Chem. B 1997, 101, 1396. (b) Calzaferri, G.; Brühwiler, D.; Megelski, S.; Pfenniger, M.; Pauchard M.; Hennessy, B.; Maas, H.; Devaux, A.; Graf, U. Solid State Sci. 2000, 2, 421.

(10) (a) Förster, T. Ann. Physik Chemie B 1948, 2, 55. (b) Valeur, B. Molecular Fluorescence; Wiley-VCH: Weinheim, 2002.

(11) Megelski; S.; Lieb, A.; Pauchard, M.; Drechsler, A.; Glaus, S. Debus, C.; Meixner, A. J.; Calzaferri, G. J. Phys. Chem. B 2001, 105, 25.

(12) (a) Hauser, M.; Klein, U. K. A.; Gösele, U. Z. Phys. Chem. 1976, 101, 255. (b) Farinha, J. P. S.; Spiro, J. G.; Winnik, M. A. J. Phys. Chem. B 2001, 105, 4879.

(13) Minkowski, C.; Calzaferri, G. Angew. Chem., Int. Ed. 2005, 44, 5325

(14) Lee, Y. J.; Lee, J. S.; Yoon, K. B. Microporous Mesoporous Mater. 2005, 80, 237.

(15) Ganschow, M.; Hellriegel, C.; Kneuper, E.; Wark, M.; Thiel, C.; Schulz-Ekloff, G.; Bräuchle, C.; Wöhrle, D. Adv. Funct. Mater. 2004, 14, 269.

(16) Chen, C.-H.; Liu, K.-Y.; Sudhakar, S.; Lim, T.-S.; Fann, W.; Hsu, C.-P.; Luh; T.-Y. J. Phys. Chem. B, 2005, 109, 17887. 